
\title{
25 Research Square \\ Spirituality and other factors associated with COVID-19 Vaccine Acceptance amongst Healthcare Workers in Cameroon
}

Neh Chang Ngasa

Faculty of Health Sciences, University of Buea

Stewart Ndutard Ngasa ( $\nabla$ stewart.ndutard3@gmail.com )

Pennine Care NHS Foundation Trust

Leticia Armelle Sani Tchouda

Faculty of Health Sciences, University of Buea

Eugénie Tanisso

Faculty of Health Sciences, University of Buea

Christabel Abanda

Laquintinie Hospital Douala, Littoral Region

Therence Nwana Dingana

Tubah District Hospital, Region Delegation of Public Health North West Region

\section{Research Article}

Keywords: Covid-19, Vaccine Acceptance, Spirituality, Health Workers, Cameroon

Posted Date: July 13th, 2021

DOI: https://doi.org/10.21203/rs.3.rs-712354/v1

License: (c) (1) This work is licensed under a Creative Commons Attribution 4.0 International License.

Read Full License 


\section{Abstract}

Background: The production of the different COVID-19 vaccines has offered hope towards controlling the pandemic. Many governments around the world have been able to secure the number of doses required for the vaccination of their entire population. In Cameroon, the government's strategy has been to secure the number of doses required to vaccinate frontline workers and other population at risk. A threat to this strategy could be vaccine hesitancy as demonstrated in previous studies. In this article we discussed the influence of spirituality on vaccine acceptance. We also examined other factors associated with vaccine acceptance amongst healthcare workers in Cameroon.

Methods: This was a cross-sectional online survey of healthcare workers in Cameroon. Data was collected using Surveysparrow and then computed into Microsoft Excel. All analysis were done using Stata 14.

Results: A total number of 371 healthcare workers took part in the survey and $45.38 \%$ indicated willingness to accept the vaccine if offered. The most common reason advanced for non-acceptance of the vaccine was negative perceptions about the efficacy of the vaccines. Independent factors associated with COVID-19 vaccine acceptance following a multivariate logistic regression included: being married (AOR 1.13, $p<0.01$ ), presence of comorbidity (AOR:2.10, $p<0.02$ ), participants who had direct contact with covid patients (AOR: $3.34, p<0.01)$. Spirituality level was not independently associated with vaccine acceptance (AOR: 1.12, $p<0.63)$.

Conclusion: COVID-19 vaccine acceptance amongst healthcare workers in Cameroon is low. This is likely to reduce the vaccine uptake amongst healthcare workers. HCWs are in the best position to influence the uptake of these vaccines by the general population, therefore educating healthcare workers on the efficacy of these vaccines might improve their acceptance.

\section{Background}

As at June 2021, the Centre for Disease Control and Prevention (CDC) reported that SARS-CoV-2 had caused more than 33 million infections and more than 61000 deaths globally[1]. Cameroon reported its first case of the virus on March 6, 2020[2] and by April 2020, the number of cases had increased to 1569, with 53 deaths[3] indicating an exponential growth in the first wave of infection. These numbers might only be an underestimation of the real burden of the disease as the diagnostic protocol for COVID-19 in Cameroon was not robust at the onset of the pandemic[4]. A second wave of the infection occurred in Cameroon in April 2021[5]. This was immediately after the African Women Nation Cup was hosted in the country. This second wave led to more deaths. According to WHO, as at June 2021 SARS-CoV-2 had led to more than 80000 COVID19 infection and more than 1300 deaths including medical professionals in Cameroon [6]. Over than 750 healthcare workers have been infected by the virus with many losing their lives[7]. 
As the virus spread around the world, WHO announced that a global approach was needed to halt its progress. Many countries shut their borders, travel restrictions were instituted, wearing of face shields, countries and regions went into lockdown and social distancing protocols were used to slow the spread of COVID-19. However, these measures were not enough to stop the spread. It became clear that the virus, unlike the closely related SARS-CoV in the 2003 outbreak, could not be contained by symptom-based screening alone and more vigorous prevention programs were needed. The development of vaccines against the SARS-CoV-2 provided the solution needed to control the virus. As at June 2021, there were 105 vaccines in the clinical development stage while 184 were at the pre-clinical development stage[8]. Many vaccines have been demonstrated to be safe and effective for human use, including Pfizer, Oxford/AstraZeneca, Moderna, Janssen, Sputnik V, Sinovac, and Sinopharm [9]. In Cameroon, Oxford/AstraZeneca, Sputnik, Johnsons and Johnsons and Sinopharm vaccines have been secured and approved for mass vaccination, with frontline healthcare workers being prioritised. The acceptance of any of these COVID-19 vaccines by the general population is an important challenge to ensure adequate uptake. Compared to the general population of Cameroon, vaccine acceptance has a crucial importance amongst Healthcare Workers (HCWs) because they are amongst the first subgroups of the Cameroonian population to have access to the vaccine. They also play an important role in fighting misinformation about vaccination among the general population. It is therefore essential to assess predictors of vaccine acceptance among HCWs.

Several predictors of vaccine acceptance have been discussed previously including the effect of spirituality on HPV vaccine acceptance in resource limiting settings[10]. Spirituality is a complex term that involves the recognition of a feeling or sense or belief that there is something greater than myself, something more to being human than sensory experience[11]. Quantitative scores like the INSPIRIT score has been developed to define levels of spirituality[12]. How these levels affect COVID-19 vaccine acceptance remains unknown.

Other predictors identified in previous studies include: sex, occupation, presence of a close relatives/friend with COVID-19 infection $[9,13]$. To the best of our knowledge no previous study has been done to determine the level of COVID-19 acceptance amongst healthcare workers in Cameroon. In this study we examined the level of COVID-19 vaccine acceptance, the effect of spirituality and other associated factors with COVID-19 vaccine acceptance amongst healthcare workers in Cameroon.

\section{Methods}

\section{Study design, setting and participants}

We conducted a cross-sectional online survey from April to June 2021 among HCWs in Cameroon; a bilingual nation located in Sub-Saharan Africa. This country is made of 10 different regions. There are approximately 1.1 physicians and 7.8 nurses and midwives per 10,000 population[14]. All healthcare workers and students working within a registered health facility within the 10 regions were eligible to take 
part in the study. An online questionnaire was created on Surveysparrow and distributed through Whatsapp groups.

\section{Sampling and data collection}

A snowball sampling technique was used to reach out to eligible participants by encouraging respondents to forward or share the online survey link with other healthcare workers. We pre-tested our online questionnaire on a group of 15 doctors and nurses prior to the commencement of data collection. The HCWs who took part in the pre-test were excluded from the study. All poorly filled questionnaires or questionnaires with too many missing data were not included in the final analysis.

\section{Outcome variables}

Our main outcome of interest was COVID-19 vaccine acceptance, and it was assessed using the question: "if offered the COVID-19 vaccine when it becomes available, would you be willing to take it?". The question had a binary response 'Yes' or 'No'.

\section{Independent variables}

Spirituality levels were assessed using the Index Of Core Spiritual Experiences (INSPIRIT score)[12]. This score was used due to its simplicity in administering to participants and also it has been found to correlate with religious involvement, influence, and hope[15]. In this study an INSPIRIT score greater than or equal to 25 was considered as high level of spirituality while a score of less than 25 was considered as low.

The following variables were also evaluated for association with COVID-19 vaccine acceptance: marital status (Single/Divorce, Married), gender (Male, Female), age, risk of infection (Self-perceived risk of COVID-19 was gauged by the question "Do you think you are at risk of getting COVID-19 in the next 1 year?" The responses were 'Yes' or 'No'); Exposure to COVID-19 (assessed by the questions "Have you directly taken care of the COVID-19 patients?" and "Have you, your family member or someone you know been diagnosed with COVID-19 excluding your patients?"), occupation, household number, setting (urban or rural) and denomination (Muslim, Christian, atheists and others).

\section{Sample Size Calculation}

The sample size was obtained using the formula for estimation of a proportion since our major outcome is acceptance of COVID-19 vaccine amongst healthcare workers.

$$
n=\frac{\left[4(\mathrm{Zcrit})^{2} \mathrm{P}(1-\mathrm{P})\right]}{\mathrm{D}^{2}}
$$

Where, 
$\mathrm{n}=$ Number of participants

$Z_{\text {crit }}=$ the standard normal deviation, corresponding to a significance criterion of $0.05(95),=1.960$

$D=$ Amount of error we will tolerate $= \pm 5 \%$

$P=$ Pre-study estimate of the prevalence of covid19 vaccine acceptance in health workers $=60 \%$

A pre-estimate value of $\mathrm{P}=60 \%$ was used. This was in accordance to a similar study in Ghana where $60 \%$ of health workers were willing to accept the COVID-19 vaccine if offered[9].

$$
\mathrm{n}=\frac{\left[4(1.960)^{2} 0.6 * 0.4\right]}{(0.1)^{2}}
$$

n= 369 participants (Healthcare Workers).

\section{Statistical methods and Data Analysis}

Data were entered into excel spreadsheet and analysed using Stata version 14 statistical software. Results were presented as frequencies, means and standard deviation (SD) for continuous variables and percentages for categorical variables. A bivariate analysis was used to obtain crudes odd ratios (OR) of factors associated with COVID-19 vaccine acceptance. Multivariate logistic regression was used to identify independent associations with COVID-19 vaccine acceptance. This was presented as adjusted odd ratios along with $p$-values. P-values were used to describe the strength of the evidence of an association.

\section{Results}

\section{Background characteristic of participants}

A total number 371 healthcare workers took part in this survey with most participants from the South West Region of Cameroon (101) (Figure 1). The participants' ages ranged from 18 to 71 years with a mean of $29.09 \pm 6.64$. A plurality of the study participants consisted of males (52.02\%) and medical doctors/medical students (63.10\%). Christians made up $89.75 \%$ of participants and minority of the participants were married (32.52\%) and lived in Rural setting in Cameroon (37.71\%). The mean INSPIRIT score of all participants was $23.35 \pm 3.88$ (Table 1 ).

\section{Acceptance of COVID-19 Vaccines and Healthcare Workers Experience with COVID-19}

Out of the $371 \mathrm{HCWs}$ who participated in the study, less than half of them (45.38\%) indicated acceptance of COVID-19 vaccines if offered. About half (135) of the participants who had self-perceived risk of COVID-19 infection indicated they were not willing to accept the vaccines. Also, 106 participants who had family/close friends infected with the virus indicated non-acceptance of the vaccines. A total number of 
participants who indicated the presence of comorbidity, 113(61.75\%) were willing to accept the vaccine. Two-thirds $(61.75 \%)$ of the participants taking care of COVID-19 patients were willing to accept the vaccines if offered (Figure 2).

\section{Reasons for non-acceptance of the vaccines}

A total number of 188 indicated a non-acceptance for the covid vaccines. The most common reason advanced by participants for non-acceptance of the vaccines was 'worry about the efficacy of the vaccine' as indicated in 66(35.10\%) participants (Figure 3).

\section{Religious concepts amongst participants}

More than half of participants considered themselves to be strongly religious, $40.33 \%$ indicated they get involved in religious activities at least once per week to several times per month. More than one third $(37.81 \%)$ on several occasions they have felt close to a spiritual force while $88.5 \%$ indicated they have had a God convincing experience during their lifetime. Overall, $44.20 \%$ indicated high levels of spirituality (INSPIRIT score $\geq 25$ ) (Table 2).

\section{Factors associated with COVID-19 vaccine acceptance}

At bivariate analysis participants with low INSPIRIT score (low level of spirituality) ( $p=0.03)$, being married $(p<0.001)$, male gender $(p=0.008)$, presence of comorbidity $(p<0.001)$, high perceived risk of COVID-19 infection $(p<0.001)$, participants who had direct contact with covid patients $(p<0.001)$ and living in urban setting $(p=0.001)$ showed strong evidence of association with COVID-19 vaccine acceptance.

Independent factors associated with COVID-19 vaccine acceptance following multivariate logistic regression included: being married (AOR 1.13, $p<0.01$ ), presence of comorbidity (AOR:2.10, $p<0.02$ ), participants who had direct contact with covid patients (AOR: 3.34, $p<0.01$ ). There was little evidence of association with living in urban settings (AOR: 1.62, $\mathrm{p}<0.05$ ).

Spirituality level was not independently associated with COVID-19 vaccine acceptance (AOR: 1.12, p<0.63) (Table 3).

\section{Discussion}

Several studies have evaluated public perceptions and acceptance of the COVID-19 vaccine. These studies focused on the general population. We assessed the level of COVID-19 vaccine acceptance, spirituality and other predictors of COVID-19 vaccine assent amongst health care workers in Cameroon.

The acceptance of the COVID-19 vaccines in our study was $45.38 \%$. This is similar to that of Verger et al. who found that about $40 \%$ of healthcare workers were willing to accept the COVID-19 vaccine if available in Belgium [16,17]. A lower acceptance of $28 \%$ was reported by Nzaji et al. in the Republic of Congo[13]. 
This observed difference could be explained by the fact that the study done in Congo was at the time when most vaccines were still at the clinical trial phase. The efficacy and side effects were unknown. This could have influenced healthcare workers' perception of the safety of these vaccines. Thus, majority opting to deny the vaccines until more data was made available.

Higher acceptance rates of these vaccines amongst health care workers have been reported in literature[18-21]. Shaw et al. reported a vaccine acceptance of $58 \%$ among health care workers in the United States[18]. The higher assent of COVID-19 vaccines in these countries could be linked to the higher awareness of the importance of these vaccines. This could have influenced the knowledge and perceptions of the healthcare workers. Also, these studies were conducted in countries with more advanced and organised public healthcare system. In Cameroon a study carried out by Dinga et al. revealed a low acceptance (15.84\%) of COVID-19 in the general population[22]. HCWs are regarded as role models and their non-acceptance of COVID-19 vaccines could indirectly influence non-acceptance in the general population. Our study also showed that concerns about the efficacy of vaccines was the main reason why health care workers were unwilling to accept the COVID-19 vaccines. This finding is consistent with previous studies in literature[9,18,23].

Low spirituality was significantly associated with COVID-19 vaccine acceptance on bivariate analysis. This was not an independent association. We found out that participants who had high levels of spirituality were more like to refuse these vaccines. This has been demonstrated in previous research where parents with much stronger religious beliefs were more likely to oppose the HPV vaccine compared to parents with less stronger religious beliefs[26]. On the other hand, Price et al. reported mothers with stronger spirituality beliefs were more likely to talk to and encourage their daughters to accept the HPV vaccines[25]. The observed differences between in the association of spirituality and vaccine acceptance in these studies and our study could be because different tools were used to measure spirituality.

Though at individual levels, spirituality might not influence vaccine acceptance, it has been demonstrated in previous studies, that public health interventions tend to be more successful if administered through faith-based organisations[26]. These programs have been categorized as faith-based or collaborative, depending on the degree of involvement by health professionals and spiritual/religious communities. In Cameroon, there exist many faith-based organisations providing healthcare services to the public. Their involvement in the public health interventions might improve vaccine uptake by the general population.

Other factors associated with COVID-19 vaccine acceptance among health care workers were participants who had direct contact with COVID-19 patients, the presence of comorbidities and being married.

Participants who had direct contact with COVID-19 patients were more likely to accept the vaccine if available. These had been previously reported in literature $[9,23]$. A probable explanation to this could be that health care workers are more likely to have witnessed the detrimental effects of the infection. Such direct contact with COVID-19 patients might instil a fear of contracting the disease. This combined with development of knowledge on COVID-19 vaccines and its efficacy acts a motivation for them to protect themselves if the COVID-19 vaccines are offered. 
In our study we found out that Health care workers who had comorbidities were more willing to accept the vaccine. This could be due to their awareness of the fact that comorbidities are a major risk factor for COVID-19 infection and a determinant of disease severity[27].

Finally, participants who were married were more likely to accept the COVID-19 vaccine. This could be due to the fear of transmitting the infection to their spouses. Furthermore, this could be due to their awareness that COVID-19 has been reported to be present in semen though transmissibility through sexual intercourse still remains unclear[28].

\section{Conclusion}

The acceptance of COVID-19 vaccine among health care workers in Cameroon is low. The most common reason for the non-acceptance of these vaccines was worry about their efficacy. HCWs with high levels of spirituality were more likely to deny the vaccines though the evidence of this association was weak. Other factors associated with COVID-19 vaccine acceptance among HCWs included: participants who had direct contact with COVID-19 patients, the presence of comorbidities and being married. These findings highlight that tailoring communication strategies towards certain sub-groups might enhance vaccine uptake among HCWs in specific and the general population.

\section{List Of Abbreviations}

\begin{tabular}{ll} 
AOR & Adjusted Odd ratio \\
\hline CDC & Centre for Disease Control \\
\hline WHO & World Health Organisation \\
\hline COVID19 & Corona Virus Disease 19 \\
\hline SARS-CoV & Severe Acute Respiratory Syndrome Coronavirus \\
\hline HCW & Healthcare Workers \\
\hline INSPIRIT & The Index of Core Spiritual Experiences
\end{tabular}

\section{Declarations}

\section{Ethics approval and consent to participate}

Ethical approval was obtained from the Institutional Review Board of the Regional Hospital Bamenda. The nature and purpose of the study was explained, and full confidentiality assured. All participants provided their consent to participate in the study by agreeing and signing our online consent form.

\section{Consent for publication}

Not applicable 
Availability of data and materials

Data can be obtained from the corresponding author upon request.

\section{Competing interests}

The authors declare no competing interest

\section{Funding}

No external funding was used to carry out this study.

\section{Authors' contributions}

NCN and TND conceptualised the project and designed the protocol and questionnaires and participated in the write of the article. SNN ran the analysis of the collected data and wrote certain sections of the article. CA, ET and LAST contributed to the write-up of the different sections of the article. All authors read and approved the final copy of the manuscript.

\section{Acknowledgments}

Our sincere gratitude goes to all the healthcare workers who volunteered to take part in this survey and are spending long hours taking care of COVID-19 patients in Cameroon.

\section{Authors' information}

Not applicable

\section{References}

1. CDC. CDC COVID Data Tracker . 2021 [cited 2021 Jun 29]. Available from:

https://covid.cdc.gov/covid-data-tracker/\#global-trends

2. Cameroon confirms first coronavirus case. [cited 2021 Jun 29]. Available from: https://www.aa.com.tr/en/africa/cameroon-confirms-first-coronavirus-case/1756866

3. Cameroon: COVID-19 Rapport de Situation N²1_23-25 Avril 2020 | HumanitarianResponse [Internet]. [cited 2021 Jun 29]. Available from:

https://www.humanitarianresponse.info/en/opérations/cameroon/document/cameroon-covid-19rapport-de-situation-n ${ }^{\circ} 2123-25$-avril-2020

4. Mbopi-Keou FX, Pondi JE, Sosso MA. COVID-19 in Cameroon: a crucial equation to resolve. Vol. 20, The Lancet Infectious Diseases. Lancet Publishing Group; 2020 [cited 2021 Jun 29]. p. 1367-8. Available from: https://youtu.be/Y- 
5. Journal du Cameroun. Cameroon reaches peak of second wave of COVID-19 infections. [cited 2021 Jul 10]. Available from: https://www.journalducameroun.com/en/cameroon-reaches-peak-of-secondwave-of-covid-19-infections/

6. Cameroon: WHO Coronavirus Disease (COVID-19) Dashboard With Vaccination Data I WHO Coronavirus (COVID-19) Dashboard With Vaccination Data. [cited 2021 Jun 29]. Available from: https://covid19.who.int/region/afro/country/cm

7. Coronavirus: 780 health workers affected in Cameroon. [cited 2021 Jun 29]. Available from: https://www.aa.com.tr/en/africa/coronavirus-780-health-workers-affected-in-cameroon/1945457

8. WHO. COVID-19 vaccine tracker and landscape. [cited 2021 Jun 29]. Available from: https://www.who.int/publications/m/item/draft-landscape-of-covid-19-candidate-vaccines

9. Agyekum MW, Afrifa-Anane GF, Kyei-Arthur F, Addo B. Acceptability of COVID-19 Vaccination among Health Care Workers in Ghana. Adv Public Heal. 2021;2021.

10. Best AL, Thompson EL, Adamu AM, Logan R, Delva J, Thomas M, et al. Examining the Influence of Religious and Spiritual Beliefs on HPV Vaccine Uptake Among College Women. J Relig Health. 2019 Dec 1 [cited 2021 Jul 1];58(6):2196-207. Available from: https://doi.org/10.1007/s10943-019-00890-y

11. Spencer M. What is spirituality? A personal exploration. Royal College of Psychiatry, United Kingdom. Available from: https://www.rcpsych.ac.uk/docs/default-source/members/sigs/spiritualityspsig/what-is-spirituality-maya-spencer-x.pdf?sfvrsn=f28df052_2

12. VandeCreek L, Ayres S, Bassham M. Using INSPIRIT to conduct spiritual assessments. J Pastoral Care. 1995;49(1):83-9.

13. Kabamba Nzaji M, Kabamba Ngombe L, Ngoie Mwamba G, Banza Ndala DB, Mbidi Miema J, Luhata Lungoyo C, et al. <p>Acceptability of Vaccination Against COVID-19 Among Healthcare Workers in the Democratic Republic of the Congo</p>. Pragmatic Obs Res. 2020 Oct [cited 2021 Jul 3];Volume 11:103-9. Available from: https://pubmed.ncbi.nlm.nih.gov/33154695/

14. WHO. WHO | Cameroon. [cited 2021 Jul 3]. Available from: https://www.who.int/workforcealliance/countries/cmr/en/

15. Newberg A, Wintering N, Waldman M. Comparison of different measures of religiousness and spirituality: Implications for neurotheological research. Religions [Internet]. 2019 Nov 1 [cited 2021 Jul 4];10(11):637. Available from: www.mdpi.com/journal/religions

16. Wang K, Wong ELY, Ho KF, Cheung AWL, Chan EYY, Yeoh EK, et al. Intention of nurses to accept coronavirus disease 2019 vaccination and change of intention to accept seasonal influenza vaccination during the coronavirus disease 2019 pandemic: A cross-sectional survey. Vaccine. 2020 Oct 21 [cited 2021 Jul 3];38(45):7049-56. Available from: https://pubmed.ncbi.nlm.nih.gov/32980199/ 
17. Verger P, Scronias D, Dauby N, Adedzi KA, Gobert C, Bergeat M, et al. Attitudes of healthcare workers towards COVID-19 vaccination: A survey in France and French-speaking parts of Belgium and Canada, 2020. Eurosurveillance. 2021 Jan 1 [cited 2021 Jul 3];26(3):2002047. Available from: https://www.eurosurveillance.org/content/10.2807/1560-7917.ES.2021.26.3.2002047

18. Shaw J, Stewart T, Anderson KB, Hanley S, Thomas SJ, Salmon DA, et al. Assessment of U.S. health care personnel (HCP) attitudes towards COVID-19 vaccination in a large university health care system. Clin Infect Dis. 2021 Jan 25 [cited 2021 Jul 3]; Available from:

https://pubmed.ncbi.nlm.nih.gov/33491049/

19. Barry M, Temsah M-H, Alhuzaimi A, Alamro N, Al-Eyadhy A, Aljamaan F, et al. COVID-19 vaccine confidence and hesitancy among healthcare workers: A cross-sectional survey from a MERS-CoV experienced nation. medRxiv. Cold Spring Harbor Laboratory Press; 2020 [cited 2021 Jul 3]. p. 2020.12.09.20246447. Available from: https://doi.org/10.1101/2020.12.09.20246447

20. Garrett L. COVID-19: the medium is the message. Lancet. 2020 Mar 21 [cited 2021 Jul 3];395(10228):942-3. Available from: https://www.

21. Richardson A. Health Care Workers' Reluctance to Take the Covid-19 Vaccine: A ConsumerMarketing Approach to Identifying and Overcoming Hesitancy. Biomedgerontology. 2020;(631):1-10. Available from: https://catalyst.nejm.org/doi/full/10.1056/CAT.20.0676

22. Dinga JN, Sinda LK, Titanji VPK. Assessment of vaccine hesitancy to a covid-19 vaccine in cameroonian adults and its global implication. Vaccines. 2021 Feb 1 [cited 2021 Jul 3];9(2):1-14. Available from: https://doi.org/10.3390/vaccines 9020175

23. Shekhar R, Sheikh AB, Upadhyay S, Singh M, Kottewar S, Mir H, et al. COVID-19 vaccine acceptance among health care workers in the united states. Vaccines. 2021 Feb 1 [cited 2021 Jul 3];9(2):1-18. Available from: https://doi.org/10.3390/vaccines 9020119

24. Shelton RC, Snavely AC, de Jesus M, Othus MD, Allen JD. HPV Vaccine Decision-Making and Acceptance: Does Religion Play a Role? J Relig Health. 2013 Dec [cited 2021 Jul 3];52(4):1120-30. Available from: /pmc/articles/PMC4616263/

25. Price KLJ, Rojas-Guyler L, Vidourek RA, Nabors L. A Preliminary Study of Mothers' Social Support, Spirituality, Knowledge, and Acceptability of the HPV Vaccine for Daughters. 2013.

26. Oman D, Neuhauser L. Public Health Education, Promotion, and Intervention: Relevance of Religion and Spirituality. Why Relig Spiritual Matter Public Heal. 2018 [cited 2021 Jul 13];2:211-23. Available from: https://link.springer.com/chapter/10.1007/978-3-319-73966-3_12

27. Rod JE, Oviedo-Trespalacios O, Cortes-Ramirez J. A brief-review of the risk factors for covid-19 severity. Rev Saude Publica. 2020 [cited 2021 Jul 3];54. Available from: 
28. Machado B, Barcelos Barra G, Scherzer N, Massey J, Dos H, Luz S, et al. Presence of SARS-CoV-2 RNA in Semen-Cohort Study in the United States COVID-19 Positive Patients. 2019 [cited 2021 Jul 3]; Available from: https://doi.org/10.3390/idr13010012

\section{Tables}

Table 1: Sociodemographic characteristics of health care workers stratified by Covid Acceptance

\begin{tabular}{|l|l|l|l|}
\hline Variable & Acceptance & Non-acceptance & Total \\
\hline Age (Years) & $29.86 \pm 5.34$ & $28.32 \pm 6.89$ & $29.09 \pm 6.64$ \\
\hline N & 200 & 168 & 368 \\
\hline Household Number & $3.81 \pm 3.18$ & $3.83 \pm 2.92$ & $3.82 \pm 3.06$ \\
\hline N & 168 & 187 & 355 \\
\hline INSPIRIT score & $22.85 \pm 3.97$ & $23.77 \pm 3.77$ & $23.35 \pm 3.88$ \\
\hline N & 203 & 168 & 371 \\
\hline Gender & & & \\
\hline Male & $100(51.81)$ & $93(48.19)$ & 193 \\
\hline Female & $68(38.20)$ & $110(61.80)$ & 178 \\
\hline Occupation & & & \\
\hline Medical doctor/student & $135(57.69)$ & $99(42.31)$ & 234 \\
\hline Nurse/Nurse student & $10(26.32)$ & $28(73.68)$ & 30 \\
\hline Laboratory technicians & $13(30.23)$ & $30(69.77)$ & 43 \\
\hline Public health specialist & 0 & $10(100)$ & 10 \\
\hline Pharmacist & 0 & $6(100)$ & 6 \\
\hline Others & $10(25)$ & $30(75)$ & 40 \\
\hline Denomination & & & \\
\hline Muslim & $21(55.26)$ & $17(44.74)$ & 38 \\
\hline Christian & $151(45.35)$ & $182(54.65)$ & 333 \\
\hline Marital status & & & \\
\hline Single & $95(37.70)$ & $157(62.30)$ & 252 \\
\hline Married & $70(60.3)$ & $46(39.66)$ & 116 \\
\hline Setting & & & 140 \\
\hline Rural & $75(53.57)$ & $65(46.43)$ & 231 \\
\hline Urban & $138(59.74)$ & $93(40.26)$ & 109 \\
\hline Presence of comorbidity & & & \\
\hline Yes & $61(92.42)$ & $5(7.58)$ & $99(90.83)$ \\
\hline No & $10(9.17)$ & & \\
\hline & & & \\
\hline
\end{tabular}


Table 2: Frequency table for religious concepts amongst participants

Spirituality Concept

Percent (\%)

How strongly do religious are you? $(\mathrm{N}=360)$

Not at all

Not very strong

Somewhat strong

Strong

Time on spent religious Activities $(\mathbf{N}=367)$

Once per year or less

Once per month to several times per year

17.44

Once per week to several times per month

Several times per day to several times per week

Have you ever felt close to a powerful spiritual force? $(\mathrm{N}=365)$

Never

10.96

Once or twice

27.95

Several times

37.81

Often

23.29

How close are you to God $(\mathbf{N}=\mathbf{3 6 8})$

I don't believe in God

Not very close

5.98

Somewhat close

39.4

Extremely close

53.53

Report of God convincing experience $(\mathrm{N}=371)$

No

I don't know

2.42

Maybe

5.88

Yes

88.5

Agreement with the statement "God dwells within you"( $\mathbf{N}=368)$

Definitely disagree

3.26

Tend to disagree

2.41

Tend to agree

16.58

Definitely agree

78.53

Spirituality Level $(\mathrm{N}=371)$

LOW (INSPIRIT < 25)

High (INSPIRIT $\geq 25$ )

55.80

44.20

Table 3: Factors associated with Covid19 vaccine acceptance amongst HCWs in Cameroon 


\begin{tabular}{|c|c|c|c|c|c|}
\hline Variable & & $\begin{array}{l}\text { Crude } \\
\text { ORs }\end{array}$ & $\begin{array}{l}\mathrm{P}- \\
\text { value }\end{array}$ & $\begin{array}{l}\text { Adjusted } \\
\text { OR }\end{array}$ & $\begin{array}{l}\mathrm{P}- \\
\text { value }\end{array}$ \\
\hline \multirow{2}{*}{ Marital status } & Married & 2.51 & $<0.001$ & 1.13 & 0.01 \\
\hline & Single/Divorce & 1 & & & \\
\hline \multirow[t]{2}{*}{ gender } & Male & 1.73 & 0.008 & 1.43 & 0.19 \\
\hline & Female & 1 & & & \\
\hline \multirow[t]{2}{*}{ Age group } & $>30$ & 2.38 & 0.001 & 1.20 & 0.55 \\
\hline & $<=30$ & 1 & & & \\
\hline \multirow[t]{2}{*}{ Presence of Comorbidity } & Yes & 2.51 & $<0.001$ & 2.10 & 0.02 \\
\hline & No & 1 & & & \\
\hline \multirow[t]{2}{*}{ High risk of infection } & Yes & 2.32 & 0.001 & 1.61 & 0.12 \\
\hline & No & 1 & & & \\
\hline \multirow{2}{*}{$\begin{array}{l}\text { Friend/Family infected with } \\
\text { covid }\end{array}$} & Yes & 1.10 & 0.79 & 0.66 & 0.12 \\
\hline & No & & & & \\
\hline \multirow[t]{2}{*}{ Occupation } & Direct contact & 4.62 & $<0.001$ & 3.34 & 0.01 \\
\hline & No contact & 1 & & & \\
\hline \multirow[t]{2}{*}{ Household number } & $<4$ Persons & 1.14 & 0.53 & 1.1 & 0.83 \\
\hline & $>=4$ Persons & & & & \\
\hline \multirow[t]{2}{*}{ Setting } & Urban & 1.71 & 0.001 & 1.62 & 0.05 \\
\hline & Rural & 1 & & & \\
\hline \multirow[t]{2}{*}{ Denomination } & Muslem & 1.01 & 0.9 & 1.01 & 0.90 \\
\hline & Christians & 1 & & & \\
\hline \multirow{2}{*}{ Spirituality level } & Low & 1.58 & 0.03 & 1.12 & 0.63 \\
\hline & High & 1 & & & \\
\hline
\end{tabular}

Figures 


$$
\mathrm{N}=371
$$

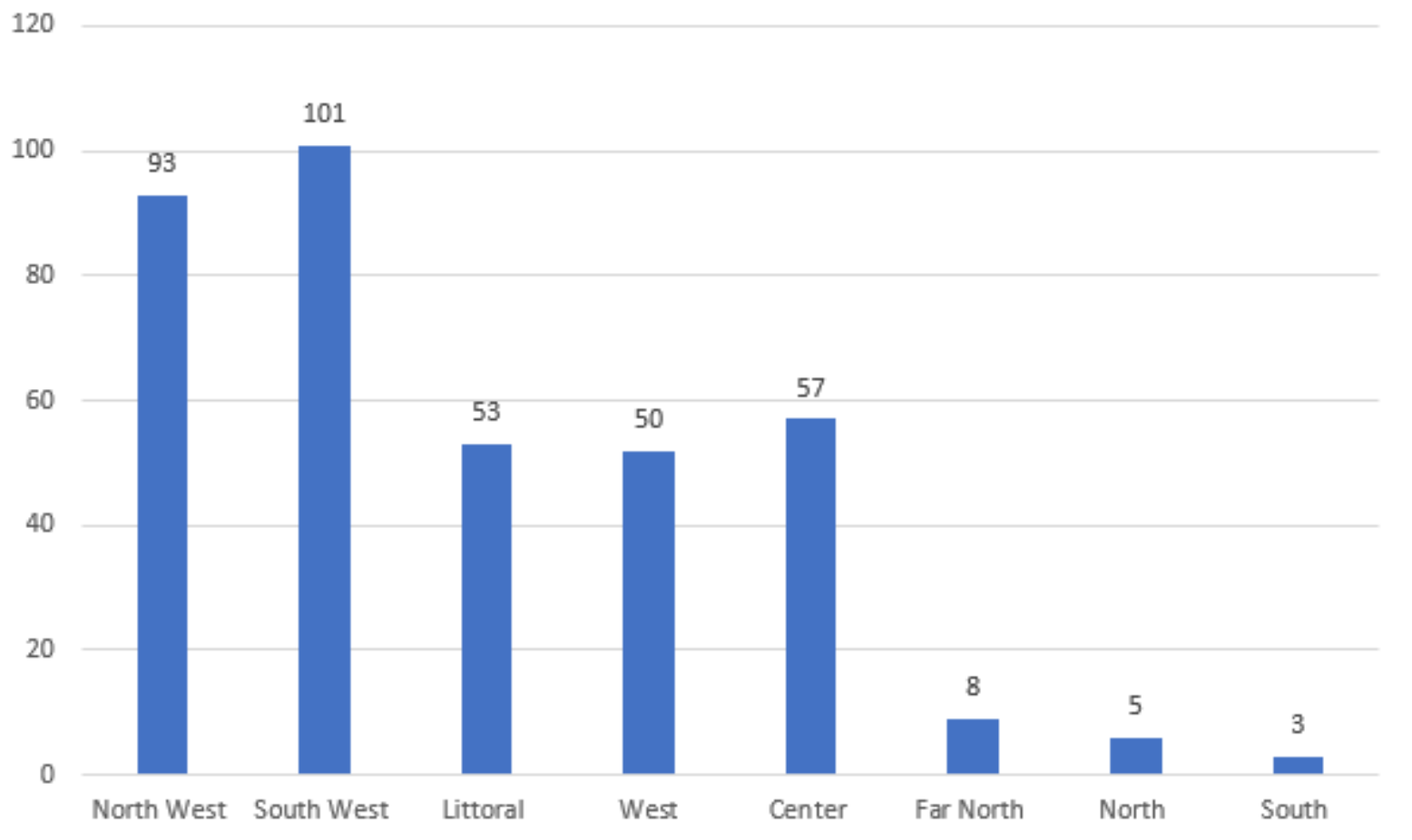

\section{Figure 1}

Frequency distribution of participants by the different regions in Cameroon

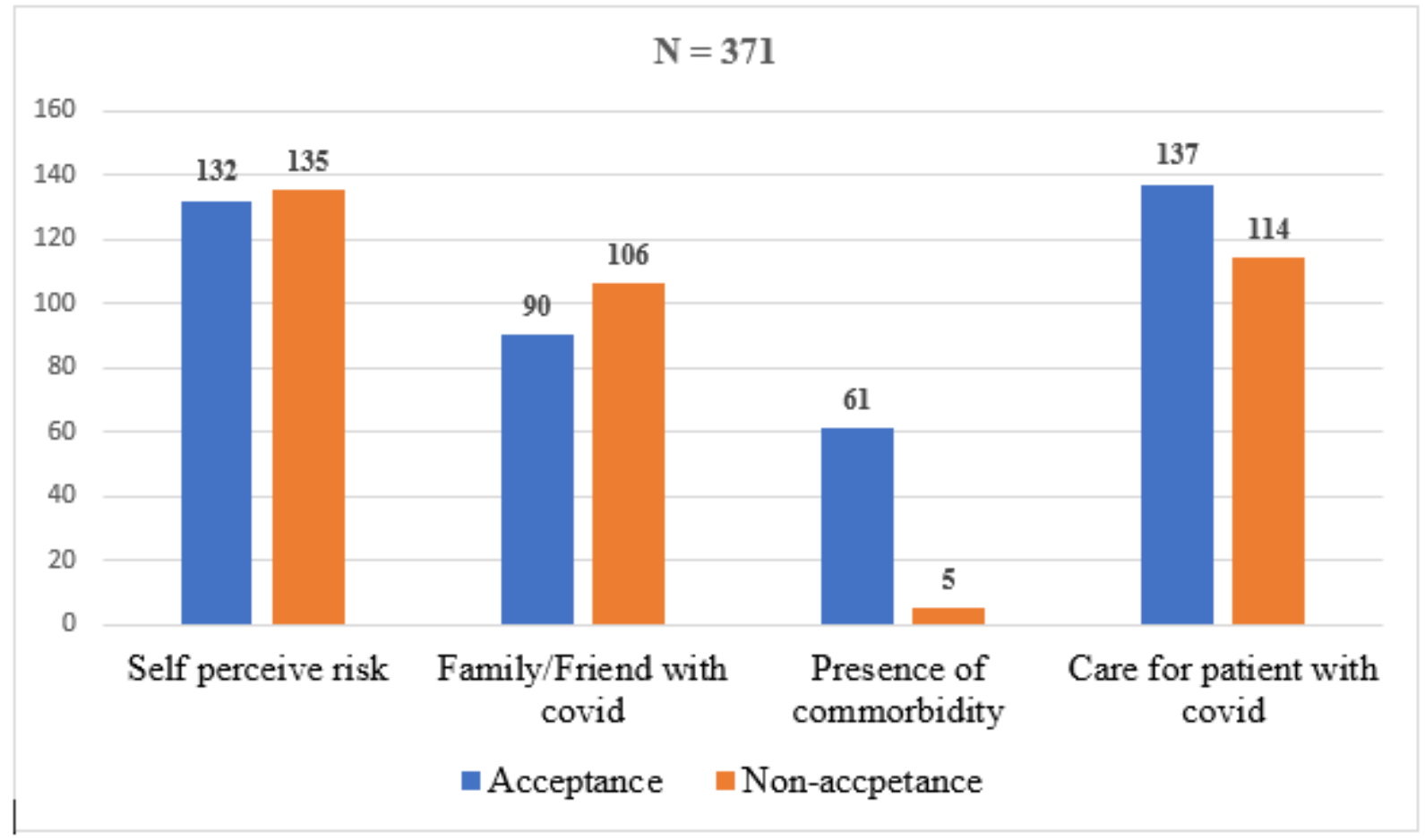

Figure 2

Frequency of healthcare workers' experiences according to COVID-19 vaccine acceptance 
Reasons for non acceptance in pecentages (\%), $\mathrm{N}=188$

Worried about the rapidity with which the vaccine was created

Worried about efficacy of vaccine

I do not think I need the vaccine

Worried about the adverse effect

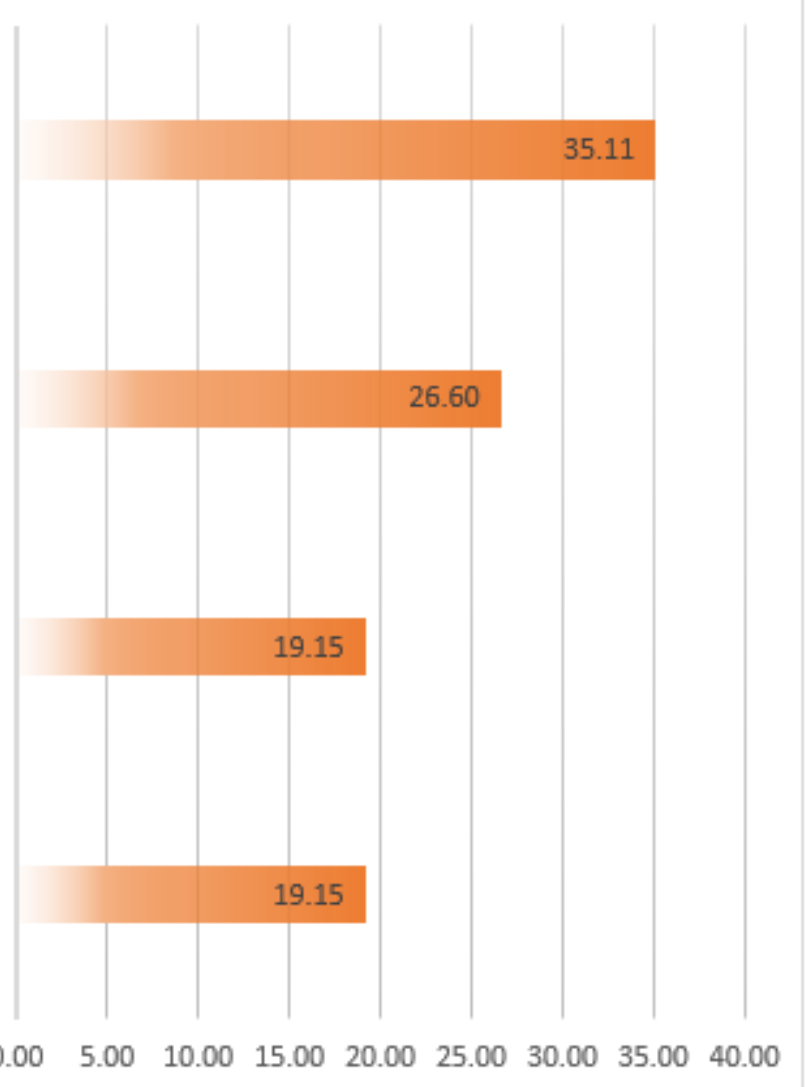

\section{Figure 3}

Distribution of the reasons for non-acceptance of COVID-19 vaccines 